\title{
REGENERATING URBAN SPACES UNDER PLACE-SPECIFIC SOCIAL CONTEXTS: A COMMENTARY ON GREEN INFRASTRUCTURES FOR LANDSCAPE CONSERVATION
}

\author{
MATTEO CLEMENTE, FABIO BIANCONI, MARCO FILIPPUCCI, LUCA \\ SALVATI
}

\begin{abstract}
:
This study investigates the issue of green infrastructures in contemporary cities, adopting a strategic vision for increasingly complex metropolitan regions. Green infrastructures play an important role in ecological services and biodiversity preservation, improving significantly the quality of life of residents and visitors. The social dimension of gardens and parks at local (e.g. urban district) scale and green infrastructures at larger spatial scales is also addressed, fostering the relationship between local communities and urban landscapes. With economic crisis, urban parks are increasingly considered a primary component of integrated strategies for urban regeneration with a bottom-up approach, addressing the demand for "natural landscape" in peri-urban areas. By recovering public spaces with social purposes and providing a comprehensive strategy for aesthetic improvement of common goods, the analyzed case studies give examples of specific measures for promoting environment-friendly urban regeneration strategies under place-specific social contexts.
\end{abstract}

\section{Keywords:}

Urban Gardens; Urban Regeneration; Public Spaces; Green Infrastructures, Biodiversity.

JEL Classification: C38, 018, R58

\section{Authors:}

MATTEO CLEMENTE, Sapienza University of Rome, Department of Architecture and Design, Via Flaminia 359, I-00196 Rome., Italy, Email: matteo.clemente@uniroma1.it

FABIO BIANCONI, University of Perugia, Department of Civil and Environmental Engineering, via G. Duranti, 93, I-06125, Perugia, Italy, Email: fabio.bianconi@unipg.it MARCO FILIPPUCCI, University of Perugia, Department of Civil and Environmental Engineering, via G. Duranti, 93, I-06125, Perugia, Italy, Email: marco.filippucci@unipg.it LUCA SALVATI, Council of Agricultural Research and Economics (CREA), Via Santa Margherita 80, I-52100 Arezzo, Italy, Email: bayes00@yahoo.it

\section{Citation:}

MATTEO CLEMENTE, FABIO BIANCONI, MARCO FILIPPUCCI, LUCA SALVATI (2017). Regenerating Urban Spaces under Place-specific Social Contexts: A Commentary on Green Infrastructures for Landscape Conservation. International Journal of Social Sciences, Vol. VI(2), pp. 18-31., 


\section{Introduction}

Processes driving urban expansion are related to multiple socioeconomic forces, making the analysis of urban morphology functions a challenging and complicated issue (Bruegmann, 2005; Cohen, 2006; Couch et al., 2007). Historical or long-established urban contexts remain heavily influenced by a complex interplay between these factors and transforming landscapes which would justify the inherent difficulty of explaining and interpreting the uniqueness of each city under specific social conditions.

Green Infrastructures (GI) are defined as an ecosystem (or a network of ecosystems) with specific parts, needs, functions and services. Benedict define Green Infrastructures (GI) as "an interconnected network of green space that conserves natural ecosystem values and functions and provides associated benefits to human populations" (Benedict and McMahon, $2000 ; 2006)$ Aspects related to ecological coherence and connectivity play an important role in ensuring the normal functioning of ecosystems, and this is essential to providing ecosystem services such as food, air quality, carbon sequestration, flood management, water treatment, climate change mitigation, and soil erosion prevention (European Commission, 2010; Whitford et al. 2001). The European Union has issued directives supported by strategic documents aimed at developing Green Infrastructures in Europe within the overall EU 2020 Biodiversity Strategy, with the final aim to promote requalification of degraded ecosystems by 2020. Taken together, general objectives of a $\mathrm{Gl}$ are promotion of ecosystem health and resilience, contributing to biodiversity conservation and enhancing in turn ecosystem services (Naumann et al., 2011) An additional objective is to improve quality of life through environmental, social and economic factors, based on multifunctional use of natural capital (European Commission, 2012). The EU Working Group on GI strategy has evdenced that Gls also promote integrated spatial planning protecting multi-functional zones by incorporation of habitat restoration measures into land-use plans and policies (Mell, 2010; 2011). Ultimately, GI can benefit human populations and contribute to a more sustainable economy based on healthy ecosystems delivering multiple benefits and functions.

Urban greening include practices of urban forestry, agriculture, farming and gardening. Generally speaking, practices of urban farming allow self-production of food plants inside peri-urban areas, urban green areas or even on the external part of buildings (e.g. top roofs). Urban agriculture includes various experiences, starting with "urban vegetable gardens", i.e. areas for cultivation within the public parks and allocated by some municipalities on free loan to citizens. In addition to providing products for family consumption, these "community gardens" contribute to preserve green interstitial spaces between the built-up areas mostly uncultivated and leave in a state of decay. Alongside the urban vegetable gardens implemented on public spaces, there are an increasing number of private areas destined to cultivation, including roofs of apartment buildings, courtyards and housing balconies, involving an increasing number of residents in gardening activity.

Another form of edible green into the city is the vertical farming project, the so called "Urban Farming Food Chain", launched as a pilot project in Los Angeles in 2008. It consists of foodproducing wall panels mounted on the walls of buildings, growing fresh products (without the use of pesticides) at four locations in and around downtown Los Angeles, inclusive of the Central City East (Skid Row) area. The project aims at replicating these activities in other cities to provide immediate access to fresh products, and also an opportunity for increasing 
community services and local attainment to agriculture.

In Europe, and especially in countries dominated by rural areas such as Italy, the longstanding tradition of farming was recently merged with the increasing demand for urban agriculture, representing a paradigmatic example for many other cities in the continent. Since World War II, relevant transformations in land-use have accompanied the socioeconomic development of Italy, influencing both natural and anthropogenic landscapes and modifying the typical features of extensiveness and environmental compatibility characterizing Italian agriculture. Nowadays, more than fifty years ago, the agrarian landscape has evolved with a much greater speed than the remote past. Coastal urbanization and industrialization of the inner areas, infrastructural development and the most recent urban diffusion, as a result of an inexhaustible drift of the economy towards advanced tertiary sectors and changes in consumer preferences and lifestyles - in both urban areas and rural districts - have given a significant input to the transformation of territories.

Especially from the 1970s onwards, agriculture has progressively lost the role of territorial presidium in the most accessible areas close to cities. Mechanization, irrigation, and capitaldriven industrial development have led to a land-use intensification that can still be seen in the monoculture landscapes typical of the Po plain, northern Italy, characterized by the scarcity of natural elements. The contraction of agricultural surfaces and values over time has not only affected economically marginal, mountainous or scarcely accessible areas, but also more accessible districts specialized in trade and industrial production, which have been invested by speculative urbanization leading to low-density urbanization with a mix of landuse that leads to entropic and mixed peri-urban landscapes.

Green infrastructure networks are proposed as key planning tools to containing dispersed urbanization around cities. At the same time, urban agriculture may preserve urban voids from high-density building and informal settlements, maintaining a vital role for agriculture. To promote the creation of urban gardens and regulate the procedures for assigning and managing the areas destined to urban farming, a protocol has been signed in 2008 by ANCI (Association of Italian Municipalities) with the environmental groups called "Italia Nostra" and "Res Tipica", both active in landscape preservation. This protocol is now active in several cities in Italy, including Milan, Bologna, Parma, Turin, Naples, Andria, Barletta, Nuoro, with a growing number of citizens involved in the initiative. Earlier studies based on statistical data shows that Italian urban gardens in 2013 tripled in respect with 2011, rising from 1,3 to 3,3 million of square meters of land owned by municipalities.

Social practices related to urban agriculture are not limited to areas assigned by municipalities, but also cover marginal areas, residual urban spaces on river banks, or close to the railways, occupied by the initiative of citizens without a license. At this regard, the movement of activists called "guerrilla gardening" was acting in several urban spaces occupying flowerbeds or abandoned plots of land for growing plants or crops.

\section{2 (Re)discovering the main socio-environmental functions of urban gardens}

Urban gardens and parks play a significant action in climate change mitigation, promoting adaptation strategies to global and local warming. At the same time, Gls play an important role for the reduction of emissions, prevention of hydro-geological damages, soil protection, 
improvement of air quality and the conservation of genetic resources better suited to cope with extreme weather conditions. The resilience to worst climate conditions is linked to biodiversity; preservation of traditional varieties and the use of agro-ecological management systems in urban agricultural productions represent an effective way to maintain food productivity and environmental sustainability in urban areas. Since the genetic heritage is the basis of food security and health, it is worth mentioning that along the last century, more than $75 \%$ of the genetic diversity of agricultural cultivation has been permanently lost.

Since urban areas revealed sensitive to environmental degradation due to high human pressure, the aim of urban gardening and improvement of Gls is to promote a new way toward a post-carbon society and urbanization, through the diffusion of new lifestyles and policy/management models involving social groups of active citizenships fighting for preservation of local varieties.

In this line of thinking, the 'biodiversity' notion should be analysed considering the peculiarity of local territory and place-specific socioeconomic conditions, the environmental context overall and the priorities set out in both country and European strategies addressing environmental protection and preservation of Nature 2000 sites. By this way, the socioeconomic context in which urban gardens will be established is particularly relevant, focusing on protection of native species that do not conflict with economic purposes and cultural needs of the gardens, or native species able to control harmful species (e.g. insects, molluscs, fungi) and limitation in the use of chemical synthetic compounds for their control.

The ecological networks established on residual green spaces bordering cities provide a broad-spectrum on urban ecosystem services, and highlight the environmental benefits offered to local communities; Gls therefore require a comprehensive strategy to properly define and develop a public intervention according to environmental measures for the preservation of biological diversity in cities.

Implementing urban gardens preserving local biodiversity actually means encouraging changes in social behaviours, proposing at the same time a practical support for the development of land management practices that help e.g. to reduce emissions through a network of urban green spaces. The urban gardens are part of these green spaces. The relationship between users and clients improves the environmental awareness of local communities.

\section{The Social Dimension of Urban Gardens}

Urban gardens can be interpreted as indirect tools promoting active citizenship in urban voids, supporting social networks and participation (European Environmental Agency, 2011; Glover, 2004). Urban gardens can become real social spaces where meeting people from different social and age groups (Glover et al., 2005). They constitute a pole of aggregation and participation in social life: while urban farmers take care of their field, people exchange ideas and opinions, rediscovering new forms of sociality and informal relationships (Kim and Kaplan, 2004).

Gardens for educational activities are also increasing within schools and prisons; gardens with a rehabilitation function such as those for medical purposes, horticulture activities to support rehabilitation programs for people with disabilities are also increasingly diffused in urban contexts. The therapeutic function of garden crops correlates with the theory of taking 
care of a living organism as a plant, improving self-esteem of patients and contributing to regain an active role in local communities.

On the one hand, urban gardens represent a great opportunity for municipal administrations to recover abandoned and degraded areas, making them clean and productive and tearing them off from dirty and lurking conditions; on the other hand, they foster public participation in the activity of local government (Mabelis et al., 2009; Ferris et al., 2001). Realizing green infrastructure in urban areas strengthens the sense of community and re-occupation of abandoned or relict sites, strengthens ties through actions voluntarily supported by local societies and contributes to counteract exclusion and isolation in local communities (Magnaghi, 2000).

\section{$4 \quad$ Regenerating Urban Spaces}

Green infrastructures, often supported by public funding (Regional, Country or European regulations), represent a great opportunity for urban regeneration (Moffat et al., 2010) and renewal. Several projects intended to rebalance urban metabolism and metropolitan landscapes, have producing structural systems in contemporary cities, sometimes with great iconic and representative value.

Examples are the New York High Line, which has become a famous place frequented by locals and tourists; the system of parks and public spaces along the Madrid Rio, the Rose Fitzgerald Kennedy Greenway in Boston, the Buffalo Bayou Promenade, and the interventions to build up urban gardens in many European cities (Figure 1).
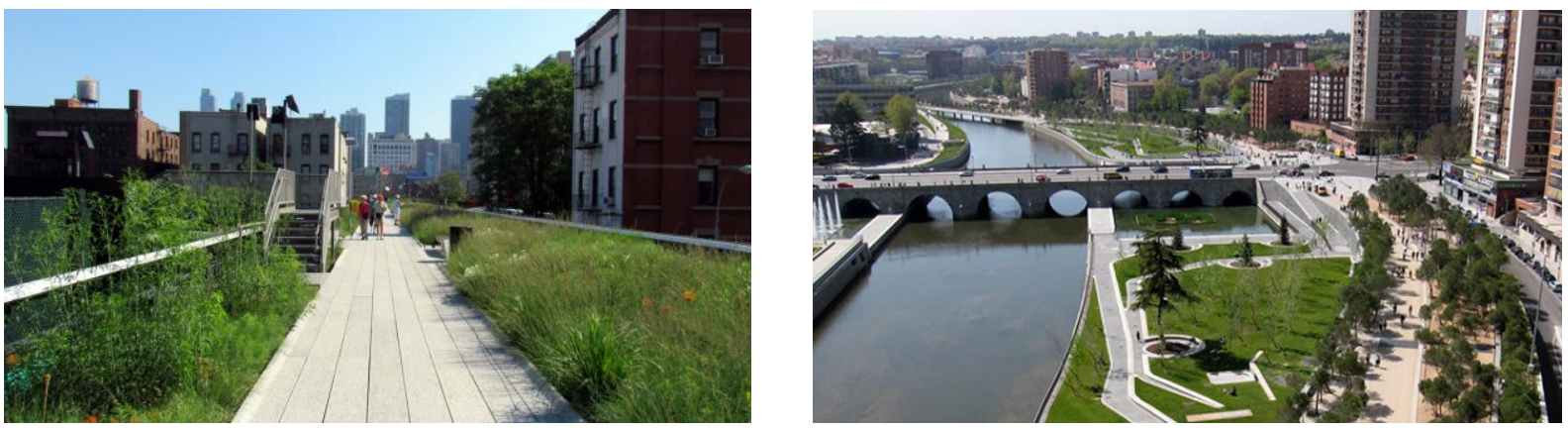

a

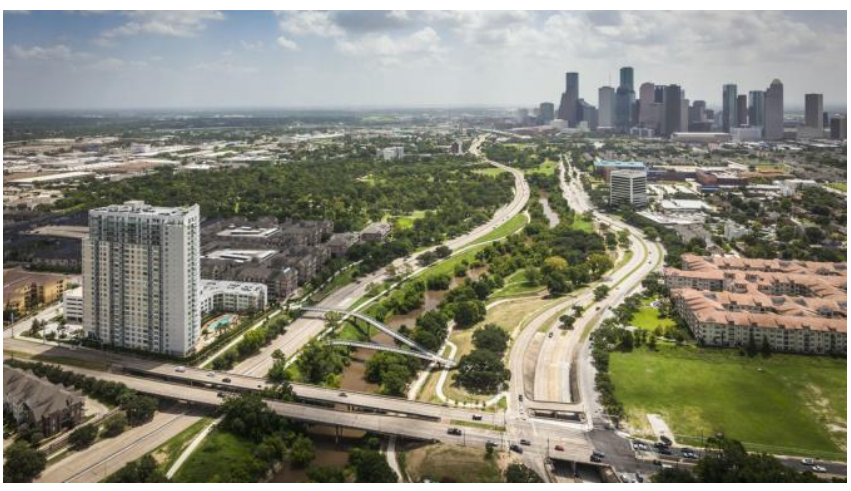

C

b

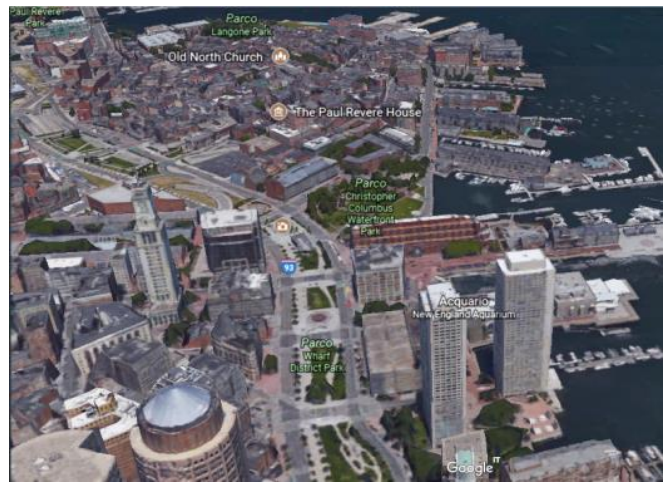

d

Figure 1: a) New York High Line (Image: creative commons); b) Madrid Rio (photo by West8); c) Buffalo Bayou Promenade, (photo by SWA Group); d) Boston, view by google 
earth of the Rose Fritzgerald Kennedy Greenway.

Even the policy of building urban gardens into the cities, according to a reverse process that starts from the bottom, or from the involvement of citizens in the realization of small local interventions, contributes to the creation of a green network (Holland et al. 2004) that adds to the primary network of green infrastructure.

Apart from the great value of the vegetation within urban spaces, as factors contributing to psychological well-being of the residents, these projects have fostered new social practices and original uses of open spaces. Climate change mitigation, biodiversity conservation and environmental re-qualification become support issues promoted by green networks, including new cycle paths, urban functions and opportunities for enjoying public spaces in contact with nature. In their multifunctional dimension, new pedestrian pathways become attractive for private investors, local stakeholders, who can engage in the same recreational and commercial activities that contribute to making urban environments more and more vital and attractive.

A combined action of top-level governance and active community participation, becomes a strategy for retrieving abandoned areas, refurbishing neighborhoods and revitalizing parts of degraded cities, involving planning authorities and policy makers with responsibilities ranging from the local to the continental level (Naumann et al., 2011). The green infrastructures project assumes the value of urban regeneration, namely a strategy for improving the quality of life of citizens in terms of "smart city". The bottom-up action of urban gardens project moves towards the same goal. They fit into urban voids or in public green areas without maintenance, representing a strategy for retraining degraded or abandoned urban areas, improving the quality of life of local communities, in the light of "resilient cities". When referring to green infrastructures within cities, zero-scale urban redevelopment interventions are essentially based on public investments, contrary to what happened in the construction of modern and contemporary cities, which are most developed on private investment on constructible urban areas. In this historical junction, with hard access to local funding due to the economic crisis, it has become necessary to look at the possibilities offered by European programs. Other sources of funding are represented by national or regional calls, which provide occasional resources for local authorities to carry out interventions of urban regeneration.

\section{The latent relationship between urban gardens and green infrastructures: two case studies}

Based on these premises, two projects promoting the multifunctional value of Gls and urban gardens as a strategy of urban regeneration are presented and discussed with the final aim to grasp the latent relationship between urban gardens and green infrastructures. The first project includes a proposal submitted by Italia Nostra under the European Union LIFE Program. The second project includes a proposal of the Municipality of Perugia for the "urban requalification of the periphery", related to the "extraordinary program" inspired to Italian architect Renzo Piano vision on sewing of urban fabric. In the latter case, the granting funds were devoted to finance projects for the suburbs 'characterized by economic and social 
marginalization, building degradation and shortage of services', with projects submitted by provincial capitals and metropolitan cities.

\section{The Italian Project of the "BioDiverse Urban Gardens" prepared by "Italia Nostra"}

"Urban gardens" is a national project of "Italia Nostra", which is the result of an agreement signed by $\mathrm{ANCl}$ (Association of Municipalities of Italy), joined with Coldiretti and the "Campagna Amica" Foundation. The "BioDiverse Urban Gardens" project promotes urban gardens in Italy with particular attention to the theme of biodiversity and the preservation of local traditions and culture, by defining methodologies and operating practices, starting from the guidelines developed by the Faculty of Agriculture of the University of Perugia. Starting from the field campaign promoted by Italia Nostra, the project was aimed at developing a pathway to connote urban gardens to better enable them to preserve and increase biodiversity. Objective is to come to light by the sample taken into consideration - 30 Municipalities and more than 3,000,000 square meters of urban gardens - their function and potentiality to plan and test demonstrative and replicable solutions able to preserve and give value to the different aspects of biological wealth that coexist and mingle in the urban context.

These proposal have stimulated a thorough discussion at local scale, giving rise to a set of original hypotheses and practical frameworks for a new development model of local territories. Planned interventions will be developed at each garden, at two conceptual scales: (i) urban landscape and (ii) ecological network, for which the agronomic and culturalhistorical knowledge are integrated with the knowledge about bio-geographic, phytogeographical, and geo-botanical local contexts. These actions will be implemented in a parallel session with a process of support, awareness and environmental education that put the citizens at the centre of the urban environment preservation. They are considered "citizens keepers" for the preservation of native species and traditional cultivars at risk, for the defence of "BioDiverse Urban Gardens" brand - to be assigned to those urban gardens that meet the criteria mentioned above - and for their participation at the active monitoring of cities (the so called program for 'Citizen science monitoring'), accompanied by a system of virtual collection of historical images of urban gardens.
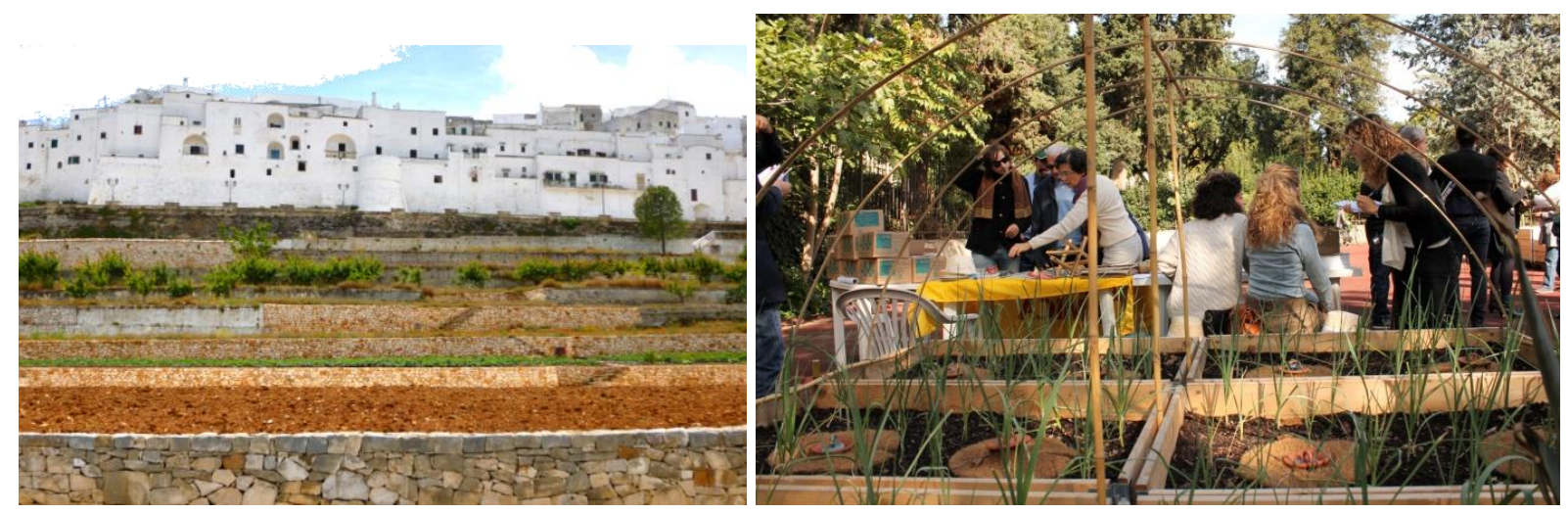

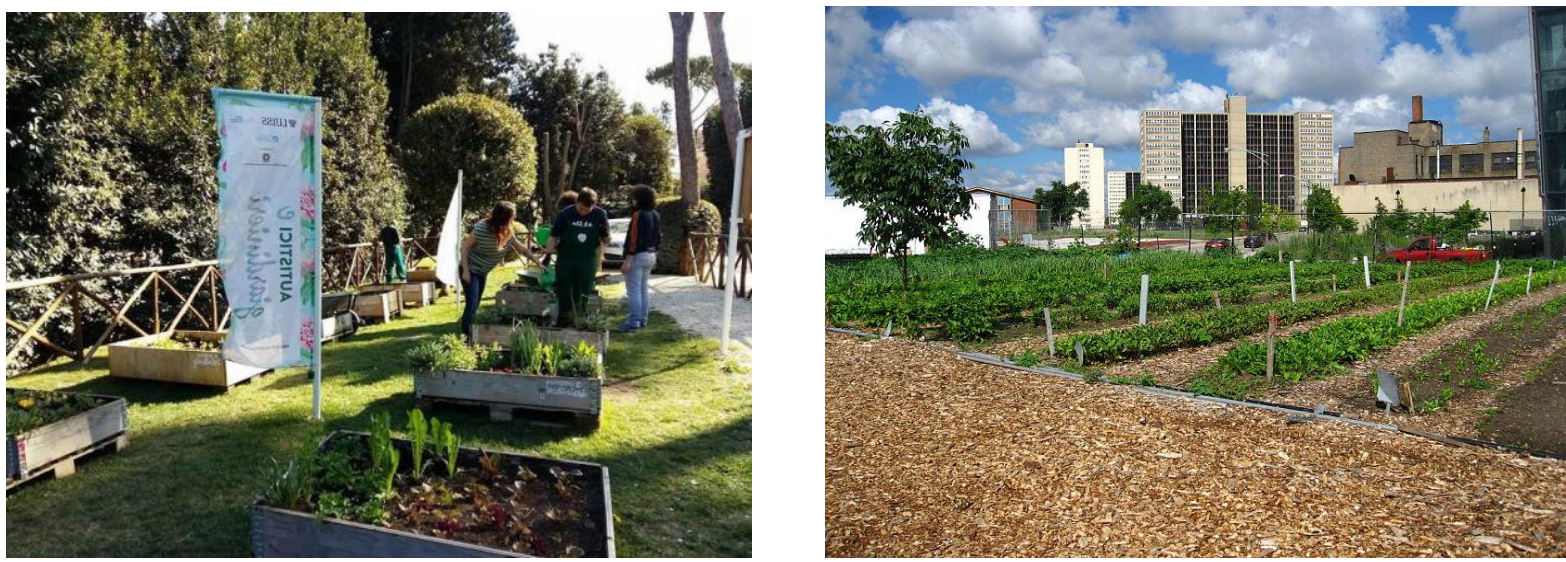

Figure 2: a) Project of Italia Nostra for Urban Gardens in Ostuni; b) Urban Gardens in Firenze; c) Vegetable gardens for autistic people in Perugia (photo Beatrice Marucci). d) Vegetables urban gardens in Chicago (image: Linda N., creative commons)

\section{An Urban Regeneration Project for an urban district in Perugia, central Italy}

The project has been elaborated for the extraordinary program requalifying urban peripheries in Italy, addressed to all the metropolitan cities and provincial capitals and entitled "New proposals for the organisation of the Special Program for an intervention to re-qualify the urban area and the safety of the suburbs"'. The project was drawn up in collaboration between the Department of Civil and Environmental Engineering and the Municipality of Perugia and entered the list with a total requested amount of $16,388,790.60$ euros funded by national grants. The proposal was finally financed, and it is foreseen to start in the coming months. The project area is a semi-central area of Perugia (in the neighborhood there is the directional center and the Piazza del Bacio designed by Aldo Rossi), where, due to the presence of the railway station, phenomena of environmental degradation and social inequalities increased over time. The theme of the project is the regeneration of the two districts of Fontivegge and Bellocchio, separated by railways and, more in general, the reconnection of the downstream area of the station with the rest of the city.

The idea is to create a public space to promote urban vitality of the entire district, becoming an attractor for the local community. The aim of the project is to retrieve urban spaces, in the new relationship between man and environment, redrawing urban landscape for a new image of the city.

The proposal consists of a series of strictly integrated and easily implemented interventions as they are mainly made up of public buildings (including a library, a new neighborhood center, and redevelopment of green spaces that function as a link between the various elements of intervention), and a series of "widespread" interventions (video surveillance, public lighting, in addition to those of a social nature mainly intended for young people), aiming at improving the level of living, security and aesthetics of the area. Taken together, the project can be understood as an urban "seam" operation to obtain urban quality based on the targeted reuse of existing buildings and the redevelopment of public connection spaces. 
The most interesting aspect of the proposal is the theme of the "green infrastructure", which recaptures the upstream green areas, with public spaces in front of the railway area and the natural areas beyond it. In addition to this green infrastructure, a large area dedicated to BioDiverse Urban Gardens has been planned, which, for the very high number (more than 400 gardens) and the central position in the city, could give Perugia a primacy position among Italian cities.

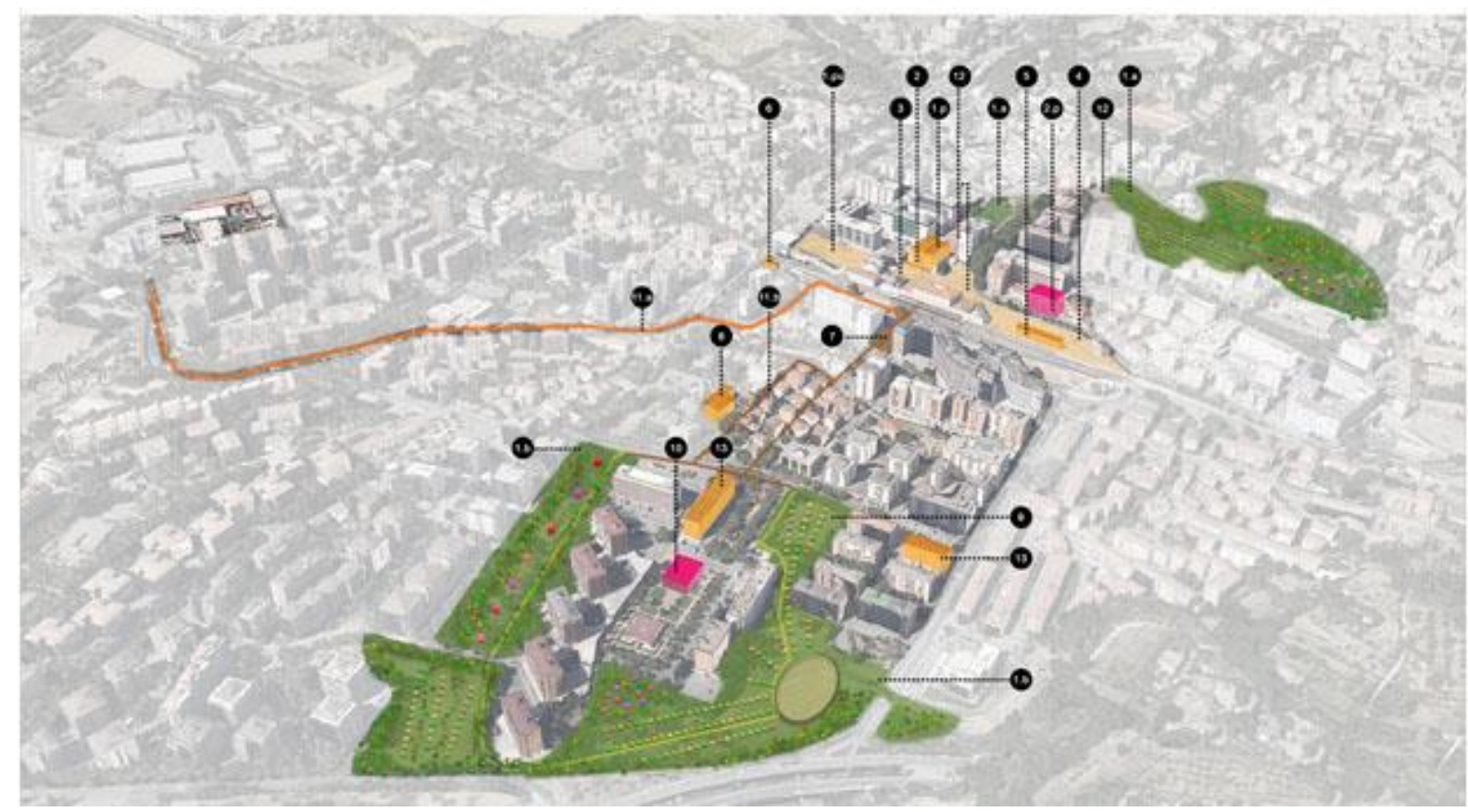

Figure 3. View of the area project for the urban regeneration of Fontivegge, Perugia.

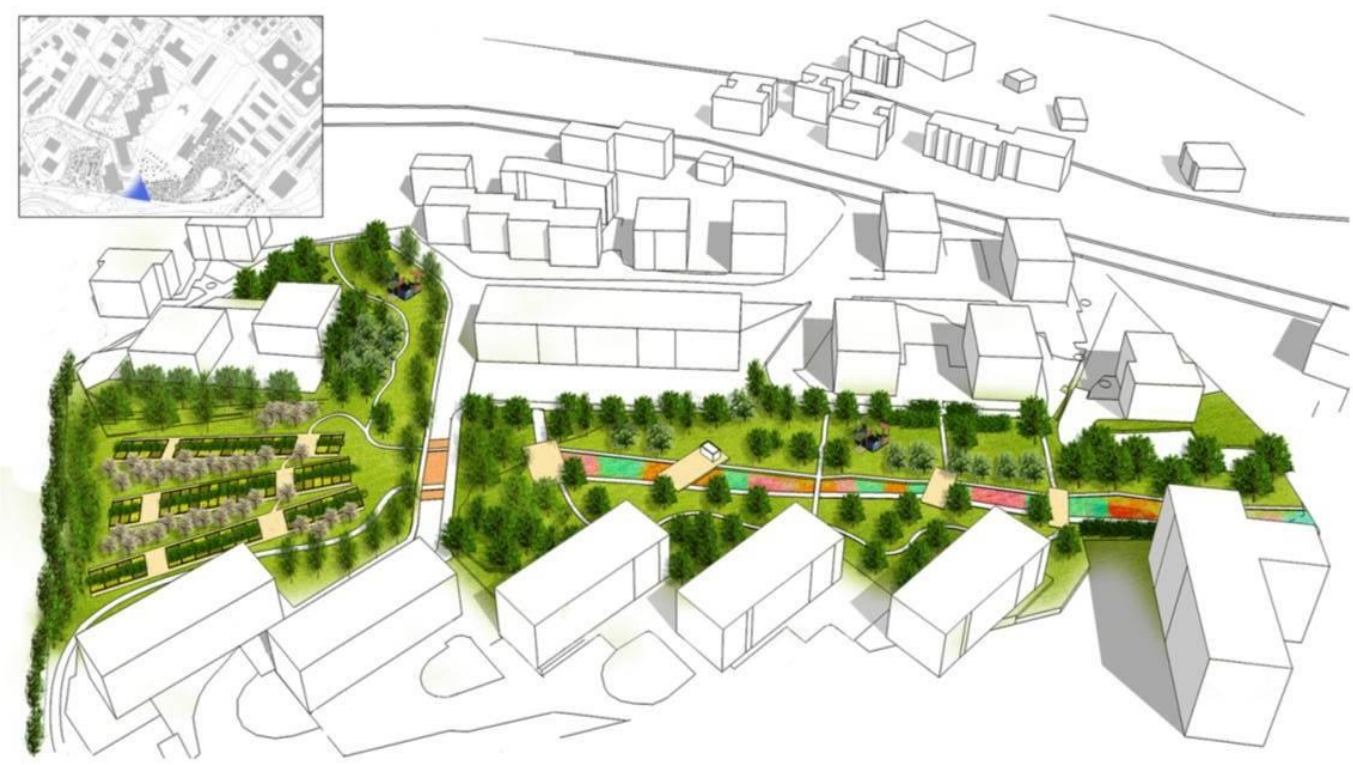

Figure 4. Landscape project for the Foibe Park in Perugia elaborated by the Department of Civil and Environmental Engineering (DICA). 
The Green Infrastructure Project is treated as a multifunctional strategy that combines the idea of increasing habitat and connectivity to native flora and fauna, as well as cyclo-pedonal fruition of the area. The design of urban gardens has also been dealt with in an innovative way: definable "BioDivers" gardens, where urbanization does not eradicate native wild species from the garden, but tries to manage and preserve ecosystem biodiversity. In particular, buffer zones were planned with spontaneous herbaceous species and hedges with native species, as well as the use of horticultural and officinal plants for the benefit of pollinating insects. Such infrastructures, in their flowering and fruiting cycles, can take on an appealing centrality for the colors, flavors and smells that characterize them.

\section{Discussion}

In the projects presented and discussed here, the notion of Urban Gardens has been conceived in multi-level and innovative way by new tools made available to administrators and citizens. The peculiar characteristic of the gardens, being Urban Gardens "BioDiverse" includes a design devoted to the protection of diversity of local varieties and biodiversity of native flora and fauna, which, in the logic of small communities and the urban environment, become elements of identity and valorization of the urban landscape. The projects foresee to develop, test and demonstrate a systemic approach for connecting urban green spaces with citizens through the planning of Biodiverse Urban Gardens, suited to the preservation of biodiversity and native crops in urban environments. The two proposals will act with a bottom-up approach on the demand side with actions dedicated to the relationship between urban gardens and citizenship, including different functions in an integrated way: the ecological function, the bio-ecological connection, the social dimension and the urban regeneration.

The Biodiverse Urban Gardens are conceived as a strategy to face the environmental challenges related to the sustainability of urban settlements, through the strengthening of green urban networks and the promotion of totally new urban green spaces. A widespread citizens' participation through social and professional networks can establish fruitful connections with the administrative and political bodies.

Urban gardens represent an interesting model of collaboration between public and private actors. Compared to the strategy of Green Infrastructures, which have been preferentially planned from above and implemented through public funding, urban gardens can form a place-specific biodiversity network with key social impact, through micro-interventions involving citizens in the management and maintenance of green commons, saving public resources. The main differences between Green Infrastructures and Urban Gardens, are in the scale of intervention: in the first case large-scale unit projects are foreseen, with major investments by public administrations; in the second case, small local projects can be realized with the involvement of small, networked communities, with very small investments. Green infrastructure units consider the city in terms of "smart city", while the most widespread and interstitial interventions of urban gardens seem to be a "resilient strategy", with even more significant social implications.

Using a strategy in line with the European Biodiversity Guidelines can implement and activate urban regeneration processes, enhancing the local territory at the same time. The BioDiverse Urban Gardens, in this way, may be considered as potential elements of a fruitful network among citizenship and dissemination tools about the wealth of biodiversity in the 
urban environment. Urban gardens allow the preservation of the landscape, ensuring the presence of agricultural land that maintains a connection with the original aspect of the land and with the oldest traditions. By linking territory to society, it is possible to raise awareness among citizens, as individuals and social groups, on the need to safeguard and re-qualify the "common good" through self-management processes of public wealth, seeking in parallel to fulfil the social demand for "landscape ", by recovering public spaces with social uses and with the overall aesthetic improvement of the cities (Clemente, 2017).

\section{Conclusions}

Urban gardens stand as a possible solution to a sustainable use of land, where the garden culture, free from its productive purposes, is bound to a cultivation always determined by natural techniques and guided by the principles of environmental sustainability. The ultimate goal is to promote a sustainable and competitive development of the territory, through integrated models where social commitment positively impacts consumption and production, for the communities that live in (or are attracted to) those places. Even in times of crisis and lack of public funds, using new approaches to urban planning and territory governance, not just oriented to consumption growth, but promoting new social relationships in public spaces (Clemente 2015; Clemente et al. 2017), cities can become places where they can experience new forms of living, working and spending leisure time in a more sustainable way.

Success landscape conservation policies are increasingly intertwined with the effectiveness of sustainable socioeconomic development strategies. The multifaceted factors, eminently multi-disciplinary and investing various fields of knowledge, need to be addressed in a more synergistic and integrated way, grasping the uniqueness of the evolution of each local community in its complex relationship with the available natural resources and allowing the necessary coordination between sectoral policies that has so far been lacking or ineffective.

\section{Reference}

BENEDICT, M.A. \& MCMAHON, E.D. (2002). Green Infrastructure: Smart Conservation for the 21st Century. Renewable Resources Journal, Autumn Edition, 12-17.

BENEDICT, M.A. \& MCMAHON, E.D. (2006). Green Infrastructure: linking landscapes and communities. Washington, DC: Island Press.

BRUEGMANN, R. (2005). Sprawl: a compact history. Chicago, US: University of Chicago Press. https://doi.org/10.7208/chicago/9780226076973.001.0001

CLEMENTE, M. (2015), I/ paesaggio come strategia di social innovation, in Proceeding of the Conference "Per la costruzione del paesaggio futuro: Necessità di agire", San Venanzo, Perugia, 2014. Roma: Franco Angeli.

CLEMENTE, M.; PILI, S.; SATERIANO, A.; SALVATI, L. (2017), Periurban Landscape in a time of crisis, In: Clemente M., Biasi R., Salvati L. (Edt.), Crisis Landscape. Opportunities and weaknesses for a sustainable development, Milano: Franco Angeli.

CLEMENTE, M. (2017), Urban Natures for Public Spaces, in "Proceedings of the International Conference on Changing Cities III Spatial, Design, Landscape \& Socio-economic Dimensions", (Editor Aspa Gospodini), Syros-Delos-Mykonos Islands, Greece -June 26-30, 2017, Thessaloniki: Grafima Publishing. 
COHEN, B. (2006). Urbanization in Developing Countries: Current Trends, Future Projections, and Key Challenges for Sustainability. Technology and Society 28 (1-2), 63-80. https://doi.org/10.1016/j.techsoc.2005.10.005

COUCH, C.; PETSCHEL-HELD, G.; LEONTIDOU, L. (2007). Urban sprawl in Europe: landscapes, land-use change and policy. Oxford. Uk: Blackwell. https://doi.org/10.1002/9780470692066

EUROPEAN COMMISSION (2010). Towards a Green Infrastructure for Europe: Developing new concepts for Integration of Nature 2000 into the wider countryside.

EUROPEAN COMMISSION (2012). Science for Environment Policy, The multifunctionality of Green Infrastructure, In-depth Reports, Bruxelles.

EUROPEAN ENVIRONMENTAL AGENCY (2011). Green Infrastructure and territorial cohesion. The concept of green infrastructure and its integration into policies using monitoring systems. EEA Technical Report No 18/2011. Luxembourg: Publications Office of the European Union.

FEKADE, W. (2000). Deficits of formal urban land management and informal responses under rapid urban growth, an international perspective. Habitat International 24(2), 127-150. https://doi.org/10.1016/S0197-3975(99)00034-X

FERRIS, J.; NORMAN, C.; \& SEMPIK, J. (2001). People, land, and sustainability: Community gardens and the social dimension of sustainable development. Social Policy \& Administration, 35(5), 559-568. https://doi.org/10.1111/1467-9515.t01-1-00253

GLOVER, T. (2004). Social capital in the lived experiences of community gardeners. Leisure Sciences, 26, 143-162. https://doi.org/10.1080/01490400490432064

GLOVER, T., SHINEW, K., \& PARRY, D. (2005). Association, sociability, and civic culture: The Democratic effect of community gardening. Leisure Sciences, 27, 75-92. https://doi.org/10.1080/01490400590886060

HOLLAND, L. (2004). Diversity and connections in community gardens: A contribution to local sustainability. Local Environment, https://doi.org/10.1080/1354983042000219388

KIM, J. \& KAPLAN, R. (2004). Physical and psychological factors in sense of community. Environment and Behavior 36(3): 313-340. https://doi.org/10.1177/0013916503260236

MABELIS, A.A. \& MAKSYMIUK, G. (2009). Public Participation in green urban policy: two strategies compared. International Journal of Biodiversity Science \& Management 5(2):63-75. https://doi.org/10.1080/17451590902978251

MAGNAGHI, A. (2000). I/ progetto locale, Turin: Bollati Boringhieri.

MELL, I.C. (2010) Green Infrastructure planning - integrating connectivity and multifunctionality with linear and large scale landscape developments. Journal of Chinese Landscape Architecture, 9(1), 131-143.

MELL, I.C. (2011). Green infrastructure planning: a contemporary approach for innovative interventions in urban landscape management, Journal of Biourbanism, 1: 29-39.

MOFFAT, A.J.; PEDIADITI, K. \& DOICK, K.J. (2010). Monitoring and evaluation practice for brownfield regeneration to greenspace initiatives. A meta-evaluation of assessment and monitoring tools. Landscape and Urban Planning 97: 22-36. https://doi.org/10.1016/j.landurbplan.2010.04.007

NAUMANN, S.; MCKENNA, D.; KAPHENGST, T. et al. (2011). Design, implementation and cost elements of Green Infrastructure projects. Final report. Brussels: European Commission

OHMER, M. L.; MEADOWCROFT, P.; FREED, K.; LEWIS, E. (2009). Community Gardening and Community Development: Individual, Social and Community Benefits of a Community 
Conservation Program, Journal of Community Practice, 17:4, 377-399, https://doi.org/10.1080/10705420903299961

WHITFORD, V.; ENNOS, A.R. \& HANDLEY, J.F. (2001). City form and natural processes: indicators for the ecological performance of urban areas and their application to Merseyside, UK. Landscape Urban Planning 20(2): 91-103. https://doi.org/10.1016/S0169-2046(01)00192-X 